\title{
Minding the Gap: How engineering can contribute to a liberal education
}

\section{Dr. Mark Valenzuela, University of Evansville}

Mark Valenzuela is Associate Professor of Civil Engineering at the University of Evansville, where he has taught since 1999. He received both his PhD and MS degrees from Cornell University in the field of structural engineering. He received his BE degree from Vanderbilt University. He is a registered professional engineer in the state of Indiana.

\section{Dr. Valerie A Stein, University of Evansville}

Valerie A. Stein is Associate Professor of Religion at the University of Evansville, where she has taught in the Department of Philosophy and Religion since 2002. She became Director of the First Year Seminar Program in 2012. She received a ThD in Hebrew Bible/Old Testament from Harvard University. She received her MA from Luther Seminary in Old Testament and a BA from Capital University in both History and Religion. Her areas of specialization include the history of biblical interpretation and the role of the Bible in culture 


\section{Minding the Gap: How engineering can contribute to a liberal education}

\section{Abstract}

The conversation about liberal education and professional education is usually about the value of liberal arts in the development of students preparing to enter a profession such as engineering, nursing or business. What if the conversation is reversed? The authors examine the question, "What can engineering contribute to the broader (and broadening) education of all our students?"

\section{Introduction}

The conversation about the value of the liberal arts for engineers is a mature one. Professional engineers and engineering educators have long advocated for the important role that liberal education has to play in the professional development of engineers. As early as 1918 the Mann Report identified the humanities as a key component of engineering education, citing the criticisms of employers of engineering graduates who lacked communication skills, business acumen, and "an understanding of men." [sic ${ }^{1}$

Sir Eric Ashy writes in 1959 that he sees a higher purpose to a humanistic education, not just in taking specific courses, but in making sense of the technology the engineer employs in its wholeness, what he calls the essence of "technological humanism.".

Samuel Florman in 1968 provides five reasons for studying the liberal arts in the introductory chapter "The Civilized Engineer" of his book Engineering and the Liberal Arts. Three of the reasons are for the personal benefit for the engineer, including an appreciation of beauty, enhancing the imagination, and the development of leadership characteristics. Two of the reasons are for the benefit of the profession and for the public good by active contribution of the engineer's technical wisdom in the solution of problems faced by society. ${ }^{3}$

More recently Lynch et al., writing in 2009, summarize aspirations for the profession that are common to studies by the American Society of Civil Engineers (ASCE), the National Academy of Engineers, and others, including enhancing the social role of the engineer and the ability to effectively deal with emerging technology to solve future social problems. ASCE's body of knowledge serves to provide a model of the educational experiences that ensures the profession will achieve these aspirations, including outcomes regarding sustainability, public policy, and globalism. Lynch et al. argue that these outcomes in particular make claims on the foundational education of civil engineering students and professionals, including foundational courses in the humanities and social sciences. ${ }^{4}$

In College Learning for the New Global Century, published as part of the Association of American Colleges and Universities' LEAP (Liberal Education and America's Promise) initiative, the National Leadership Council for Liberal Education and America's Promise promotes educational objectives for all higher education programs, including programs in professional schools, that includes knowledge of human cultures and the physical and natural world, intellectual and practical skills, personal and social responsibility, and integrative and 
applied learning. The LEAP report argues that all students need a liberal education to prepare them not only for their professional lives but also for their lives as citizens in the face of the global and complex challenges of the $21^{\text {st }}$ century. ${ }^{5}$

In many ways, the authors' institution ${ }^{\mathrm{a}}$ embodies the ideals of LEAP. The University of Evansville provides a liberal education grounded in a college of arts and sciences but integrated with a wide variety of professional programs, including those provided in a college of engineering, a college of health and education, and a school of business. The University's mission of learning resonates with the LEAP report, recognizing similar challenges of globalization and responding with a similar vision:

We are committed to the liberal arts and sciences as a basis for intellectual and personal growth. The University endeavors to prepare women and men for lives of personal and professional service and leadership. The University is aware of the challenges of living in an international community and therefore adopts a global view in its programs and its vision.

The University of Evansville seeks to fulfill this mission through its general education program, Enduring Foundations, which is composed of 11 student outcomes:

1. Critical reading and thinking

2. Engagement with imaginative expressions of the human condition

3. Knowledge of human history and the historical context of knowledge

4. Engagement with fundamental beliefs about human identity, core values, and humankind's place in the world

5. Understanding of human aesthetic creation and artistic creativity

6. Linguistic and cultural competence in a language other than one's own

7. Quantitative literacy

8. Scientific literacy

9. Understanding of core concepts of society, human behavior, and civic knowledge

10. Knowledge and responsibility in relation to health and wellness

11. An ability to think critically and communicate effectively, orally and in writing.

In addition, students are required to complete courses that satisfy writing-across-the-curriculum and three overlays: International Diversity, Domestic Diversity, and Social Responsibility. ${ }^{6}$

The First Year Seminar (FYS) is the cornerstone of the general education program at the University of Evansville. The essential learning objectives of the required course (FYS 112) include critical reading, critical thinking, and effective written and oral communication. First Year Seminar sections are different in content from each other, but each section meets these goals by encountering challenging texts and using this material as the basis for writing assignments and class discussion. This course builds upon the students' basic academic writing skills and helps them begin to understand the conventions of academic research and college-level discourse. Through FYS, students meet the requirement for the first outcome, critical reading and thinking, as well as one of the four writing-across the curriculum requirements. 
In the summer of 2012, the second author (Associate Professor of Religion, Chair of Religion and Philosophy, and Director of the University of Evansville's First Year Seminar) asked the first author (Associate Professor of Civil Engineering) to deliver the plenary lecture in the fall to large assemblies of the small seminar sections. This required lecture was meant to ground the students in a common experience that articulated a common goal for FYS, namely critical thinking. This lecture had previously been given by professors in the humanities. As the new FYS director in 2012, the second author inherited the challenge of a program staffed primarily by the faculty in the college of the arts and sciences. In 2011-12 there were 74 sections of the thenequivalent of FYS 112; only three of those sections were taught by faculty from the professional schools (one from the college of engineering and two from the college of education and health sciences). The second author was concerned that students perceived this lack of participation in FYS by the faculty of the professional schools as a lack of endorsement for the value of liberal education. ${ }^{\mathrm{c}}$ She wanted the lecture to emphasize the significance of FYS as a foundation for all areas of study at the University, and she felt that a faculty member from one of the professional programs might best be able to articulate the importance of liberal education to those students seeking a professional education. The second author approached the first author because he was a passionate and articulate supporter of FYS and had a solid understanding of the program, having taught a course that was a predecessor to the current FYS and having served on the FYS oversight committee. At the time, the second author was motivated by the usual direction of the conversation about liberal education and professional education: wanting to convince students preparing to enter a profession, such as engineering, nursing or business, of the importance of a liberal education.

\section{FYS plenary lecture}

Although the first author was mindful that the FYS audience drew from all of the majors across campus (liberal arts and non-liberal arts) and needed to address the nature and value of critical thinking, the choice of the subject matter and its treatment reflected the usual direction of the conversation about the discipline of the liberal arts in engineering. As a case study of the application of critical thinking, the lecture delves into conspiracy theories regarding the collapse of the World Trade Center Towers on 9-11. The opportunity to prepare for the plenary lecture gave the first author the motivation to seriously consider the efforts by a handful of engineers and architects to reopen the investigation of the collapse as part of the 9-11 Truth Movement by trying to engage engineering students on college campuses throughout the US.

The overall goal of the lecture was to illustrate the process of carefully examining the claims made by the 9-11 Truth Movement, beginning with the assumption that the claims were worthy of serious yet critical examination. Because the purpose of this paper is not to present the entire 50-minute lecture, a brief overview will be given of the method of examination of the 9-11 Truth claims. Untangling the conspiracist's claims naturally involved an examination of the physical evidence through the discipline of science and technology. However, it is actually the discipline of the liberal arts and social sciences that can prompt the engineer and the layperson to seriously critique the conspiracy claims. In particular, the seminal work of Dr. Richard Hofstadter, a professor of American History at Columbia University in the 1960s, is used in the FYS lecture to place the 9-11 Truth Movement in the broader context of other conspiracy theories that reflect what he termed the Paranoid Style. 
While the lecture is, by necessity, grounded in the engineered objects of the World Trade Center Towers and a sequence of physical events that can be modeled scientifically, it offers a critical reading of the conspiracy literature, in close parallel to what would be expected of students in FYS as they delve into the texts that they examine. As they develop the skills of critical reading, thinking, and writing, three attitudes were also offered at the conclusion of the lecture to serve as complements to their intellectual journey: the drive to delve deeply into the question being explored and the evidence being presented, the humility to know the limits of one's own personal knowledge and to let go of deeply held beliefs when confronted with valid evidence, and the courage to speak out for truth when confronted by ignorance and fear.

The lecture, given in the fall of 2012, 2013, and 2014, was well-received by students and FYS faculty alike, and the two authors came to realize that there is a great benefit for students in the liberal arts to hear a FYS plenary lecture given by an engineering professor. However, in reflecting on the experience we saw an opportunity to change the direction of the conversation and argue in this paper that engineering can contribute to the broader (and broadening) education of all our students.

\section{Changing the direction of the conversation}

In this particular context, the collapse of the World Trade Center Towers, understanding the engineering and science of tall buildings lies at the heart of critiquing the conspiracy claims. While the lessons of history are useful in suspecting that a claim might be invalid, ultimately some knowledge and understanding of what is technologically and scientifically possible and provable is needed to either accept or reject a claim that on surface may be convincing or plausible. When confronted by a suspicion about a claim's validity, there are several possible responses.

As evidenced in some public debates (for example, regarding responses to climate change and even the validity of climate change models), it is possible to profess to being an agnostic. ("I'm not a scientist...") Some are genuinely agnostic but perhaps are intimidated by the complexity of the problem and so do not seek to develop any further understanding. Some perhaps profess to be agnostic in order to protect deeply held world views about how the world does or ought to operate. They simply do not want to explore further and perhaps they even over-exaggerate the limits of scientific understanding ("It is impossible to know"). While some humility about the limits of one's own knowledge is healthy, rejection of any responsibility to the work of trying to learn runs counter to the very premise of liberal education. Engineers, technologists, and scientists can and should bolster a liberal education curriculum, not necessarily by making technology experts of non-engineers, but by trying to better communicate the principles and methods that engineers and scientists use to shape and understand the world. And in doing so, perhaps make the subject less intimidating and making it a little more difficult to be a complacent agnostic. Indeed, by unveiling natural and technological processes and the methods of state-of-the-art engineering and scientific reasoning, one can imagine that non-engineers will be better equipped to critically analyze claims made by experts and so-called experts. Of course, these questions are not unique to problems in engineering, science, and technology. But critical thinking skills are not learned in the abstract; these skills need to be grounded, and the grounding 
guides the questions that are asked to evaluate claims and to make decisions that affect a society that is shaped by engineering and technology.

\section{Engineering bridges between two cultures: the FYS Bridge Course}

As a result of ongoing discussions between the authors, a class (the FYS Bridge Course) is being designed that can meet the overarching FYS goals of critical reading, critical thinking, and effective oral and written communication, but with a focus on providing liberal arts students with the knowledge, attitudes, and intellectual skills so that they can fully engage in debates surrounding public works and infrastructure concerns. Designing the features of this course (the topics to be explored, the readings to be chosen, the learning activities to be assigned, etc.) is informed by the rubrics that all FYS sections use to assess student learning. Most important are the rubrics for achieving learning at the highest levels for critical reading and critical thinking. Among these are:

READING: Analysis

Engages texts. Recognizes relations among parts or aspects of a text, such as effective or ineffective arguments or literary features, in considering how these contribute to a basic understanding of the text as a whole.

READING: Discussion

Participates in academic discourse about texts. Discusses texts in structured conversations (such as in a classroom) in ways that contribute to knowledge-building and a basic, shared understanding of the text.

CRITICAL THINKING: Explanation of Issues Issue/problem to be considered critically is stated, and description begins to define terms, explore ambiguities, determine boundaries, and/or establish backgrounds.

CRITICAL THINKING: Student's Position (perspective, thesis/hypothesis) Specific position (perspective, thesis/hypothesis) acknowledges different sides of an issue. Questions some assumptions. Identifies context(s) when presenting a position. May be more aware of others' assumptions than one's own (or vice versa).

By necessity the rubrics are written such that they can be applied to the broad range of topics that fall under the FYS umbrella. Particularly relevant to the premise of the FYS Bridge course are the rubrics that address establishing the background, exploring ambiguity, questioning assumptions, and identifying context, but applied to challenges in engineering, technology, and science in society. With this in mind, the authors have selected tentatively the following topics and readings for the course:

The questions that science, engineering, and the humanities can answer... and those they can't.

Selected readings from Engineering: Its Role and Function in Human Society (Davenport and Rosenthal, editors, 1967). ${ }^{7}$ 
The Vision for Civil Engineering in 2025 (ASCE 2006) ${ }^{8}$

\title{
Uncertainty, Risk, Climate Change, and the Future (Sorting Fact, Fear, and Fiction)
}

The Essential Engineer: Why Science Alone Cannot Solve Our Global Problems

(Petroski 2010) ${ }^{9}$

The Collapse of Western Civilization: A View from the Future (Oreskes and Conway 2014) ${ }^{10}$

\section{Energy: Public Reactions and Engineering Alternatives (Or, is there really a "War on} Coal"?)

The Essential Engineer (Petroski 2010)

\section{Infrastructure: Planning for the Future (Or, "Why don't we have flying cars yet?")} The Essential Engineer (Petroski 2010)

The City of Tomorrow and Its Planning (Le Corbusier 1929) ${ }^{11}$

Transportation Improvement Program 2013-2016 (City of Evansville MPO 2013) ${ }^{12}$

\author{
Infrastructure: Maintaining (and Funding) for the Present (Or, "A stitch in time saves \\ nine.") \\ The Essential Engineer (Petroski 2010)
}

2013 Report Card for America's Infrastructure (ASCE 2013) ${ }^{13}$

The necessary background will involve not only a basic understanding of what engineers and scientists do (and their boundaries) but also basic scientific and engineering principles and approaches that these technological communities accept as standards. However, the authors also realize that this class is not meant to train scientists or engineers but is intended for liberal arts students. The emphasis of the course must not be on facts or concepts in engineering but rather on developing the intellect in such a way that students learn to think with the principles and methods used by engineers and scientists to thoughtfully engage the challenges of the $21^{\text {st }}$ century. To privilege critical thinking, coverage of engineering practices and scientific principles will be reduced in favor of exploring the technological and scientific modes of thinking.

A challenge in developing this course is finding that balance between the modes of inquiry that the FYS sections must focus on and the subject matter. This is true in any of the FYS sections, whether dealing with the feminist movement or a survey of opera. Although some technical and scientific literature will be engaged and surveyed, the choice of the literature will be founded on the underlying question of the FYS Bridge course: how can laypersons begin to make sense of claims or proposed decisions and actions that are grounded in usage of technology or scientific data? In reading the texts that are assigned, the rhetoric of persuasion will be explored, especially when the persuasive argument relies on experts, expertise, and expert opinions. But in addition, the students will be asked to read the text with the critical eyes of an engineer or scientist, even if they do not have the same knowledge base and sophistication of an engineer or scientist. 
The rubrics that have been developed for FYS embody the modes of thinking that the university feels all students who are grounded in the liberal arts should be able to employ. In the context of this FYS Bridge course, two modes seem especially appropriate to explore in depth in a course that deals with public decisions about the use of information from the engineering and science domains: ambiguity and assumptions.

Ambiguity is explored in the context of how engineers and scientists deal with uncertainty and risk. In particular, debates about directions that society will take, including how to fund infrastructure and technological initiatives, have to deal with the difficulty of predicting consequences and future performance based on empirical evidence.

Assumptions and context are also important in having honest discussions about questions related to the environment, energy, and infrastructure. While engineering and science documents will be explored, the course intends to keep the perspective broad to include a broad social spectrum (what are the effects on the poor as well as the rich, for example), long-term vision (what does this do for future generations), and examination of political orientations (how does my perspective of the role of government in a democratic society color the way I interpret engineering recommendations and scientific understanding). In order to elevate public discourse beyond partisan sound bites and internet memes, educated individuals in the $21^{\text {st }}$ century need to understand the complexity of these kinds of issues and know what kinds of questions need to be asked in order to understand them and evaluate potential solutions. Learning science and engineering will not provide clear answers. It will, however, allow students to become more fully engaged as citizens of the world who know how to critically engage arguments involving science and technology.

While various aspects of the course are still being discussed, the authors intend to have a proposal ready for the FYS Committee for possible inclusion in the offerings of FYS in Academic Year 2015-2016 at the University of Evansville.

\section{Summary and conclusions}

In his 1959 Cambridge lecture on the gulf that seemed to separate science and technology on one side and the humanities on the other, physicist and novelist C. P. Snow lamented that "There seems to be no place where the cultures meet." (Snow 1969) Although divides between communities are lamentable in and of themselves, Snow saw that this particular divide has global consequences. From Snow, closing the divide between technology and the humanities meant, in part, correcting a hierarchy where science and technology was taken for granted. But not merely for the sake of prestige, but because he saw in scientists and engineers the human capital necessary to close the divide between rich and poor, between the developed countries of the West and those countries in Africa and Asia that he saw struggling to survive in the $20^{\text {th }}$ century. ${ }^{14}$

At the University of Evansville, faculty from different disciplines recognize the opportunity to close that divide, to meet $21^{\text {st }}$ century needs. The first opportunity discussed in this paper was the invitation of an engineering professor to deliver the FYS plenary lecture, motivated in part by the usual conversation engineers have with those in the humanities: we engineers need the 
humanities to be truly a profession. But out of that experience, the authors have come to realize that the conversation can and must go in the other direction: we humanists need the insight of engineers and scientists to truly understand humanity in the $21^{\text {st }}$ century. This conversation has led to the proposal of a FYS section that seeks to introduce non-engineering students to the debates and discussions that center on the responsible use of technology and scientific information. While the proposed FYS section can address the divide that Snow describes in a way that is true to the principles of liberal education, the authors recognize that one course in a curriculum is not sufficient. All students need courses that focus on the knowledge base, experimental methods, and problem-solving practices of science and technology. However, the proposed FYS course fills a significant need: that place where two cultures can meet, and where they can begin to understand the technological problems facing the $21^{\text {st }}$ century world.

\section{endnotes}

\footnotetext{
${ }^{a}$ A small private university with over 2200 undergraduate students.

${ }^{\mathrm{b}}$ The program underwent several changes between 2011 and 2013 with the implementation of the new general education program, but the core goals remained the same.

${ }^{\mathrm{c}}$ Few general education courses are offered by the professional programs as well.
}

bibliography

1. Mann, C. R. (1918) “A Study of Engineering Education.” Carnegie Foundation for the Advancement of Teaching. Bulletin Number 11. New York.

2. Ashby, E. (1959) Technology and the Academics. St. Martin's Press: New York.

3. Florman, S. C. (1968) Engineering and the Liberal Arts: A technologist's guide to history, literature, philosophy, art, and music. McGraw-Hill: New York.

4. Lynch D. R., Russell, J. S., Mason, J. M. and Evans, J. C. (2009) Claims on the Foundation: Professionalism and Its Liberal Base. Journal of Professional Issues in Engineering Education and Practice. Vol. 135, No. 3, July 1, 2009. pp 109-116.

5. Association of American Colleges and Universities. (2007) College Learning for the New Global Century: A report from the National Leadership Council for Liberal Education and America's Promise. AAC\&U.

6. Catalog 2013-2015. University of Evansville.

7. Davenport, W. H. and D. Rosenthal, editors. (1967) Engineering: Its Role and Function in Human Society. Pergamon Press: New York.

8. American Society of Civil Engineers. (2006) The Vision for Civil Engineering in 2025. ASCE: Reston, VA.

9. Petroski, H. (2010) The Essential Engineer: Why Science Alone Cannot Solve Our Global Problems. Alfred A. Knopf: New York.

10. Oreskes, N. and Conway, E. (2014) The Collapse of Western Civilization: A View from the Future. Columbia University Press: New York.

11. Le Corbusier. (1929) The City of Tomorrow and Its Planning. Dover Publications: New York. 1987.

12. City of Evansville MPO (2013). Transportation Improvement Program 2013-2016. City and State redacted.

13. American Society of Civil Engineers. (2013). 2013 Report Card for America's Infrastructure. ASCE: Reston, VA.

14. Snow, C. P. (1969) The Two Cultures and A Second Look. Cambridge University Press: Cambridge, UK. 